\title{
Improve inspection process in tire manufacturing by using computer simulation
}

\author{
Sathitthep Sangthong ", Pattara Woraphu and Kanokbhorn Arayikanon \\ Industrial Engineering Department, Faculty of Engineering, Rajamangala University of Technology Rattanakosin, Nakorn Pathom, \\ Thailand
}

\begin{abstract}
The purity of this research was to study the feasibility of improving the quality inspection in the manufacturing of tire by focusing on the utilization process. The current plant production is continuous and there are four working groups which can be divided into 3 shifts with 24 hours produced a day (Average production capacity is 350 days per year). Improved quality inspection processes will inevitably result in unnecessary production stops. Therefore, the researchers have proposed a feasibility study on how to improve the quality of the test procedures using engineering and technology techniques. These create models that have the same functionality as the current working condition. The result was found that Model 2 could reduce unnecessary processes and also four workers per shift if the worker's wage was calculated. This model shows a cost reduction of approximately 1.68 million baht per year, as well as utilization process
\end{abstract}

\section{Introduction}

This factory case study is a big tire production company which has make-to-order manufacturing processes. Job flow is a flow shop which is the same direction from start to finish. The production is carried out by the production department and it employs around 2,000 people. The Maximum tire production capacity is about 35,000 units per day. Work scope is categorized into 4 groups of 3 running cycles for 24 hours excluding 10-15 holidays. In case of engine break down or any improvements will affect the production line greatly especially in high volume. Hence, the machine maintenance should be avoided in the peak period. If the machine needs to be repaired, it has to be done after production is finished. As for the problem mentioned above, the management team recognizes the importance of increasing productivity but not stop working. Due to limitations and conditions of the factory, Researchers propose a feasibility study on the improvement of the performance for the tire quality inspection department by using various tools in industrial engineering, problem solving and simulation to study the feasibility of improvement and find alternative ways for better decision making. To use simulation, each models can be configured to study the consequences of each model. There is efficiency measure for the existing and new working scenarios. To select an effective improvement scenario before starting the actual plan can help the business to be successful.

\section{Theories and Research}

Situational modelling is one of the best way to solve process problems. At present, the design and development of the system often rely on Modelling for analysis prior to applying to the real system. There are simulation software which can simulate the work system. Computer simulation is in the form of computer programs the principle is to create a systematic decisionmaking approach troubleshoot the system or improve the existing system is good. It is not without interference in the real process. [1] Simulation is a way to analyse performance of system which is based on interaction the intersection of several random processes. These random processes can be identified by the probability model [2] The system we are interested in may really exist. For example, if we want to improve the existing system "better" (the criteria for measuring "good") or a situation that does not exist yet. For example, changing the storage layout of a warehouse will use a rack rather than a place on the pallet. The current simulation cannot measure performance directly. In the case the numerical method cannot be determined estimation error. [3] Situational modelling is a model of the real process to learn the behavior of the real process under the conditions laid down in the analysis and evaluation the implementation of the system before the actual. [4] Yonlada Shomya and Udom Jantarajatsuk [5]. present to improved performance of the queuing process by using simulation out-patient services of Lum look Ka Hospital in Pratumthanee province, by modelling the situation and taking into account the dynamic behavior of the patient's arrival time and validation of the model with statistical

\footnotetext{
* Corresponding author: sathitthep.san@rmutr.ac.th
} 
validation techniques. Then presented the revised model in 3 approaches which can be concluded to be the best choices. The result showed that there should have an additional channel for drug dispensing and this would lead a reduction in the average number of service hours per patient by an average of $20.90 \%$ and reduced outpatient services by an average of $29.09 \%$.

\section{Operation}

\subsection{Work Study}

To study the work process of the audit department (Inspection Department) for inspection of tire quality is to understand the correct work and simulation model which should be very close to the original process. The study found that there are 5 steps in the process.

- Trimming rubber (Trimming)

- Mark and weigh (Balance Section)

- Quality Inspection 100\% (100\% Section)

- Check the balance (Uniformity Section)

- Quality Inspection 200\% (200\% Section)

The procedure of the inspection quality department is shown in Figure 1.

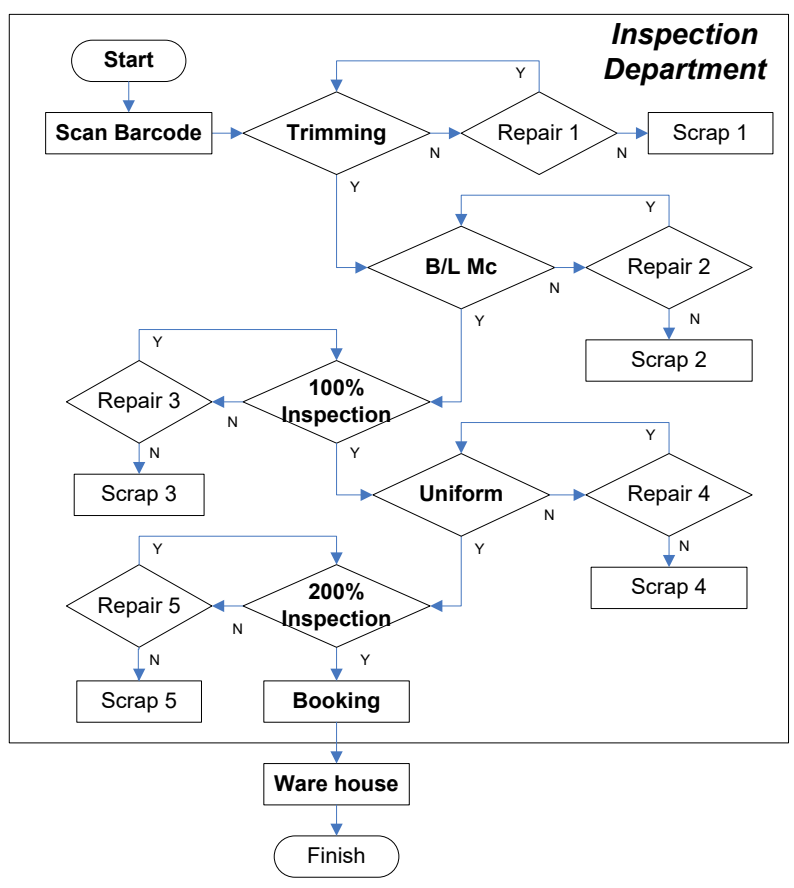

Fig. 1. Procedure of the inspection quality.

\subsection{Data collection and Analysis}

Tire Quality Inspection Department will use data from working time Monday to Friday in the morning 8 a.m. to 4 p.m. (day shift) with no break time. In day time, the data will have an interruption break period for 15 days. Most of the information is from the monitoring department's timekeeping. Quality and information generated by the machine. In order to provide statistical analysis, every data sets need to have an outlier test. The outlier will be removed before input into statistical analysis in the next step.

$$
n=[Z \alpha / 2 x S / d] 2
$$

$\mathrm{d}=$ Margin of error in estimating mean (setting $\alpha=$ $0.05)$

The appropriate sample size is 22.67 , but the data collection must be an integer, so the appropriate amount of Section $100 \%$ is 23 .

\subsection{Modelling the situation}

When data is collected as required. The next step is to find the probability distribution of the data by using Chisquare test [6] for one-way discriminant analysis. (Goodness of Fit Test)

$$
\chi^{2}=\sum_{i=1}^{k} \frac{\left(o_{i}-E_{i}\right)^{2}}{E_{i}}
$$

Table 1. Data distribution model of tire quality inspection process.

\begin{tabular}{|l|c|l|}
\hline \multicolumn{1}{|c|}{ Work station } & Amount & \multicolumn{1}{c|}{ Pattern of Data } \\
\hline Cut Tentacle & 2 & Binomial $(57,0.948)$ \\
\hline Mark and weigh & 2 & Uniform $(26,31)$ \\
\hline Quality Inspection $100 \%$ & 2 & Binomial $(71,0.923)$ \\
\hline Check Equation & 2 & Uniform $(27,32)$ \\
\hline Quality Inspection200\% & 2 & Binomial $(68,0.725)$ \\
\hline
\end{tabular}

Situational modelling needs to be closest to the real system. In order to be able to describe the various functions correctly from the analysis. Statistically, the distribution pattern of all data process simulation Modelling [7,8] is used to model the position of the tire quality inspection process.

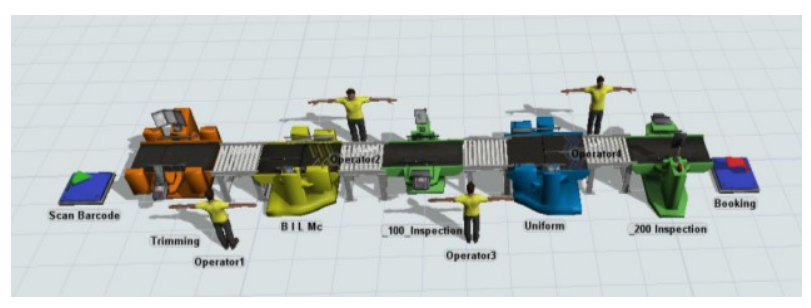

Fig. 2. Current Model Simulation

\subsection{Analysis of the accuracy of the situation model}

The process of analyzing the accuracy of the procedure is a necessary. It also requires those who understand the system thoroughly to assist in the investigation. If the generated model does not work properly with the diagram design. The improvement will result in errors. Therefore, the generated model must have a valid process flow based on the actual process and statistical tests. Comparison of the results is obtained by Welch Test Confidence Interval, the simulation model of the tire inspection department was created is close to the real 
system average at the $95 \%$ confidence level, and this model can be used instead of the real system.

\subsection{Rounding out the simulation}

System design for modelling situations requires multiple tests for accuracy and data variance. This can be calculated by the following equation

$$
R \cong R_{0} \frac{h_{0}^{2}}{h^{2}}
$$

$R_{0}=$ Number of preliminary simulation rounds

$h_{0}=$ Half width from the simulation cycle.

Introduction at the $95 \%$ confidence level,

$h=$ Acceptable $5 \%$ half width

The experimental results of the tire quality testing department were 240 hours per cycle in 8 replication experiments.

\section{Overall Result}

\subsection{Solutions of problems}

The concept of work improvement for waste reduction in the manufacturing process in the tire quality inspection department is trying to eliminate and reduce unnecessary work. There are many outstanding works from production that is redundant of working procedures. The problem is solved by $5 \mathrm{w} 1 \mathrm{H}$ technique to find solutions and then design the production process using ECRS technique. In order to reduce waste from production and increase efficiency, it is necessary to consider tackling quality control process to $100 \%$ and quality control process up to $200 \%$ quality control process in this section. The analysis can propose ways to improve tire quality inspection system in 2 ways as follows.

\subsection{Model Simulation 1}

Apply ECRS to improve performance by removing the $100 \%$ Inspection section. The newly created models are shown in Figures 3 and 4 . Figure 4 shows the procedure for inspecting the tire quality. (Simulation 1)

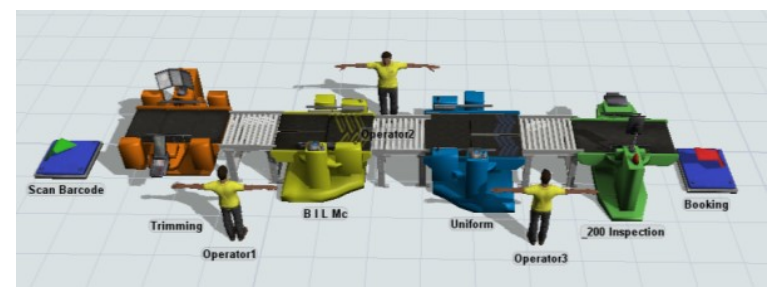

Fig. 3. Model Simulation 1

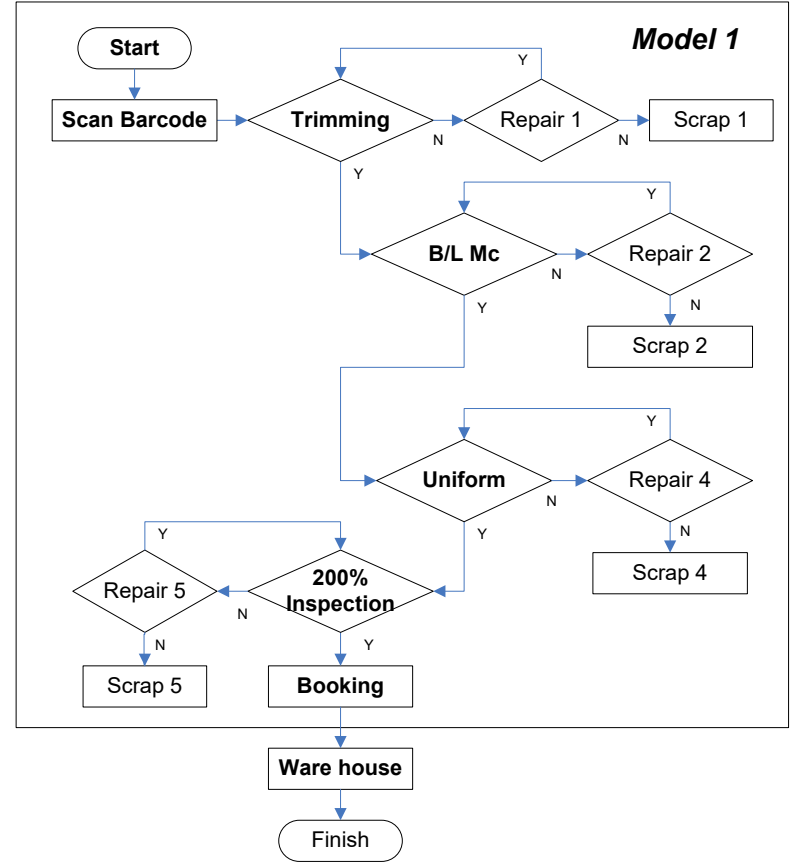

Fig. 4. Procedure for inspecting the tire quality. (Model Simulation 1)

From Tire Quality Inspection Models after improvement, the first test used 240 hours with 8 replications. The average all work sections are over $80 \%$ except for rubber cutter which has machine efficiency $75.02 \%$

\subsection{Model Simulation 2}

Using ECRS principles to improve the original functionality by eliminating the $200 \%$ Inspection section. The Model Simulation 2 is shown in Figures 5 and 6.

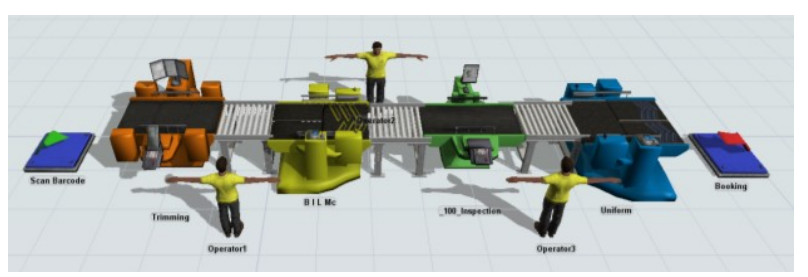

Fig. 5. Model Simulation 2 


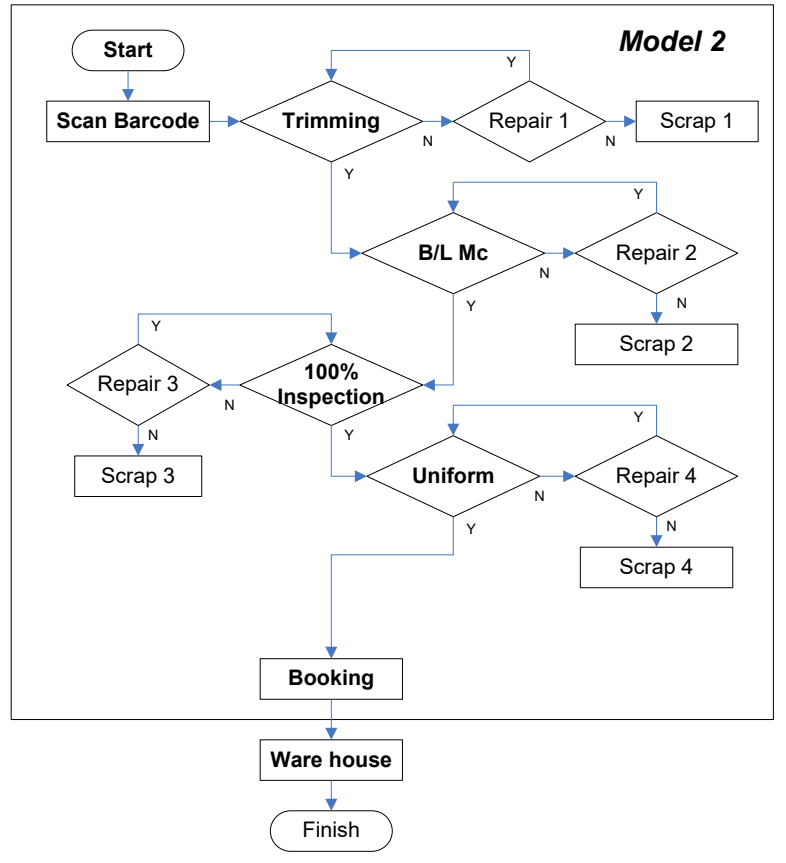

Fig. 6. Procedure for inspecting the tire quality. (Model Simulation 2)

The Model 2 was test by 240 hours of 8 replications. The machine efficiency of all work stations have average percentage more than $80 \%$ except for rubber cutter which has machine efficiency $74.89 \%$ as show on Table 2 .

Table 2. Average performance of each workstation classified by Model type.

\begin{tabular}{|l|r|r|l|}
\hline \multirow{2}{*}{ Work Station } & \multicolumn{3}{|c|}{ Machine efficiency (\%) } \\
\cline { 2 - 4 } & Cur & \multicolumn{1}{|c|}{ M.1 } & \multicolumn{1}{c|}{ M.2 } \\
\hline Cut Tentacle & 74.99 & 75.02 & 74.89 \\
\hline Mark and weigh & 83.51 & 83.56 & 84.25 \\
\hline Quality Inspection 100\% & 94.71 & - & 91.63 \\
\hline Check Equation & 85.13 & 84.64 & 85.11 \\
\hline Quality Inspection 200\% & 91.74 & 91.24 & - \\
\hline Average & 86.02 & 83.62 & 83.97 \\
\hline
\end{tabular}

After defining guidelines for improvement and the results are summarized in Table 3.

Table 3. Result of each simulation model.

\begin{tabular}{|l|c|c|c|}
\hline \multicolumn{1}{|c|}{$\begin{array}{c}\text { Situation } \\
\text { simulation }\end{array}$} & $\begin{array}{c}\text { Machine } \\
\text { efficiency }\end{array}$ & $\begin{array}{c}\text { Number of } \\
\text { employees }\end{array}$ & $\begin{array}{c}\text { Amount } \\
\text { of waste }\end{array}$ \\
\hline $\begin{array}{l}\text { Current model } \\
\text { Simulation }\end{array}$ & 86.02 & 6 & 253 \\
\hline $\begin{array}{l}\text { Model } \\
\text { Simulation 1 }\end{array}$ & 83.62 & 4 & 288 \\
\hline $\begin{array}{l}\text { Model } \\
\text { Simulation 2 }\end{array}$ & 83.97 & 4 & 279 \\
\hline
\end{tabular}

\section{Summary and recommendations}

Based on a feasibility study, the Quality Assurance Department found that the Product Inspection Division had a redundant work process between the $100 \%$
Inspection Section and the 200\% Inspection Section which will be increasing confidence for quality assurance of customers and the quality of the product slightly. If you want to improve the inspection process, the Model Simulation 2, which can cut 200\% Inspection Section out, can be a very good candidate. Using the ECRS principle and simulation model to improve performance is a guideline by creating a model to provide an improved system which cannot be tested on real situation. If we improve the inspection process based on the proposed model, it will be possible to reduce 4 workers per shift (cost reduction is about 1.68 million baht per year). Performance is closed to work situation before improvement. The Factory plant layout is very small and worth the investment.

\section{Acknowledgments}

The author would like to thank the Institute of Research and Development Rajamangala University of Technology Rattanakosin, Thailand

\section{References}

1. R.E. Rhanon, "System Simulation: The Art and Science," Prentice-hall Inc., Englewood Cliff., 1975.

2. Nelson, B. L. 2013. Foundations and methods of stochastic simulation. USA: Springer.

3. Juta Phichitlumken "Random-Simulation Basics Model to apply to solve the real problem." Department of Engineering

4. Industrial Engineering Faculty Kasetsart University Publisher of Kasetsart University.

5. Kelton, D.W., Sadowski, R.P. and Sturrock D.T., 2003, "Simulation with Arena"-3 rd ed., International Edition, McGraw-Hill, The McGrawHill Company, Inc.

6. Yonlada Shomya and Udom Jantarajatsuk "Improving queuing performance using situation simulation Case Study: Outpatient Services System Lamlukka Hospital" Industrial Engineering Faculty of Engineering King Mongkut's Institute of Technology Ladkrabang Ladkrabang Engineering Year 30 No. 1 March 2013

7. Rungrat Phisashpen, "Modeling Guide with Arena Program Revised edition," 1st edition, SEEDUCATION Co., Ltd., Bangkok, 2008

8. Maria, A., 1997, "Introduction to model and simulation", Proceeding of the 1997 Winter simulation Conference ed. S. Andradottir, K.J. Healy, D.H. Withers, and B.L.Nelson.

9. Charles Harrell, Biman K.Ghosh, Royce Bowden. "Simulation using ProModel" Boston: McGrawHill/Higher Education, c2004 